\title{
A LITTLE GOES A LONG WAY
}

\section{Service delivery in Gauteng's police stations}

Yvonne Pennington, Business Against Crime

yvonnep@bac.org.za

As part of Business Against Crime's Support Partnership for Police Station programme, service delivery in 33 of Gauteng's 121 police stations was evaluated in late 2003. The results highlight many often overlooked issues which can be simply rectified to present a user-friendly environment in which police can offer a more sympathetic and professional service. Most 'clients' had positive views of the police when leaving the station, but detectives must be assisted to improve the system of providing feedback to victims on progress with their case.

$\mathrm{F}$ or the past five years Business Against Crime's (BAC) Support Partnership for Police Station (SPPS) programme has been focused on improving service delivery at local level in an entrepreneurial manner in which the partners themselves identify and address the areas of greatest need. Each partnership comprises a willing business, a selected police station and the community served by that police station represented by the Community Police Forum (CPF). BAC facilitates the process.

The SPPS programme operates in Gauteng and Mpumalanga. In Gauteng, BAC follows priorities of the South African Police Service (SAPS) wherever possible in the selection of police stations to partner. There are currently 33 partnerships in the province (out of 121 police stations). In Mpumalanga, where BAC partners the most needy police stations in areas where big business operates, there are currently 14 partnerships with business potential for 20 (out of 92 police stations in the province).

Following a review of the programme in Gauteng in early 2003, BAC saw the need to focus all partnerships on the same service delivery criteria in order to standardise and facilitate evaluation. The three focus areas selected are those that most impact crime victims:

- the community service centre (CSC) where the victim reports the crime;

- the detective component which investigates the crime; and

- the victim support facility at the station which assists the traumatised victim of crime (Figure 1).

Figure 1: SPPS model for service delivery focus, Phase 1: 1-3 year intervention

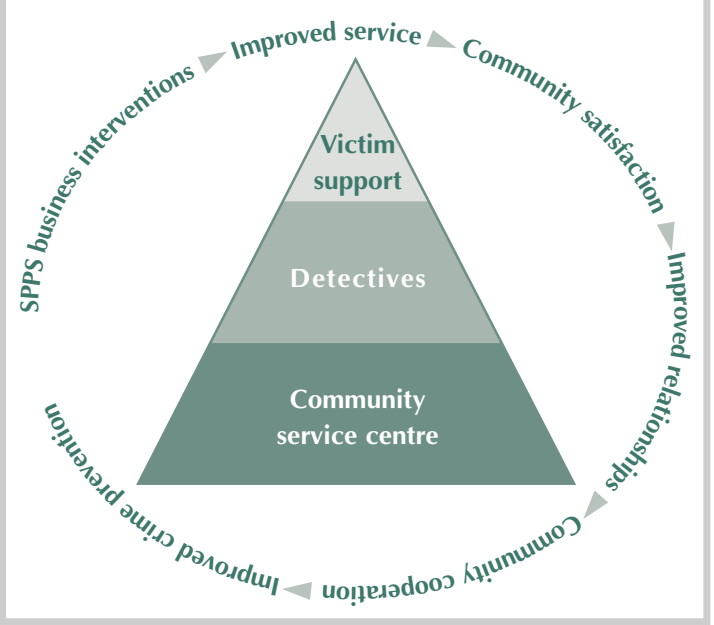


It is interesting to note that, according to the study which this article is based on, approximately $80 \%$ of people who visit police stations deal only with the CSC. The onus for excellent service delivery lies very much, therefore, with these important members of every police station.

\section{Approach to the evaluation}

A baseline evaluation was conducted by an independent evaluation specialist at 33 SPPS police stations in Gauteng during August/September 2003 (Table 1).

Four evaluators under a single supervisor conducted the research over the course of 30 days. A variety of different research approaches were utilised for the study. Given that the criteria against which the stations were assessed are primarily service-related, the research tools were designed to explore the various aspects of service and more specifically, the inter-personal service received at stations, and the nature of the station environment.

Table 1: Police stations in Gauteng where SPPS partnerships were reviewed

\begin{tabular}{|c|c|}
\hline Area Johannesburg & Area North Rand \\
\hline Johannesburg Central & Edenvale \\
\hline Hillbrow & Ivory Park \\
\hline Jeppe & Olifantsfontein \\
\hline \multicolumn{2}{|l|}{ Booysens } \\
\hline Langlaagte & Area West Rand \\
\hline Cleveland & Kagiso \\
\hline Yeoville & Krugersdorp \\
\hline \multicolumn{2}{|l|}{ Brixton } \\
\hline Sophiatown & Area Vaal Rand \\
\hline Linden & Vereeniging \\
\hline Bramley & Evaton \\
\hline Norwood & De Deur \\
\hline Sandton & Meyerton \\
\hline \multirow[t]{2}{*}{ Alexandra } & Sharpeville \\
\hline & Sebokeng \\
\hline \multicolumn{2}{|l|}{ Area East Rand } \\
\hline Alberton & Area Soweto \\
\hline Bedfordview & Diepkloof \\
\hline Katlehong & Kliptown \\
\hline Kwa Thema & Moroka \\
\hline Tsakane & \\
\hline
\end{tabular}

The Client Service Centre was assessed using a combination of environmental observation and interviews.

A questionnaire detailing minimum standards for the appearance of the CSC was completed by the evaluator. This was followed by a series of brief exit poll interviews conducted with members of the public ('clients') leaving the station. A minimum of 30 clients per station were interviewed. The sample was stratified according to the nature of the visit to the police station. This ensured that respondents could answer questions regarding the service received when reporting a crime or engaging on a crime-oriented matter.

A similar approach was used for assessing service in the rest of the station and from the detectives. An observation module was completed at the same time as the CSC observation module. In the case of the detectives, only those clients who actively engage with these officials are in a position to report on the service received. So while at the station, evaluators collected basic contact information from randomly selected crime dockets made available by the relevant officer at the station. Telephonic interviews were then conducted with clients about the service received from the detectives.

A brief observation module was formulated and completed for the victim support facility at each station. The station commander was also interviewed about the number of personnel trained in victim support, resources available and the system at the station for referring victims to specialised support services.

In total 844 exit poll interviews were conducted at all the stations and 305 follow-up interviews were conducted about the service received from detectives.

Ten criteria were measured in each of the three focus areas. The criteria started with such fundamental issues as neatness, cleanliness and tidiness, through functional layout and signage, to the skills required by police officers in order to render a consistently reliable service to members of the public. 


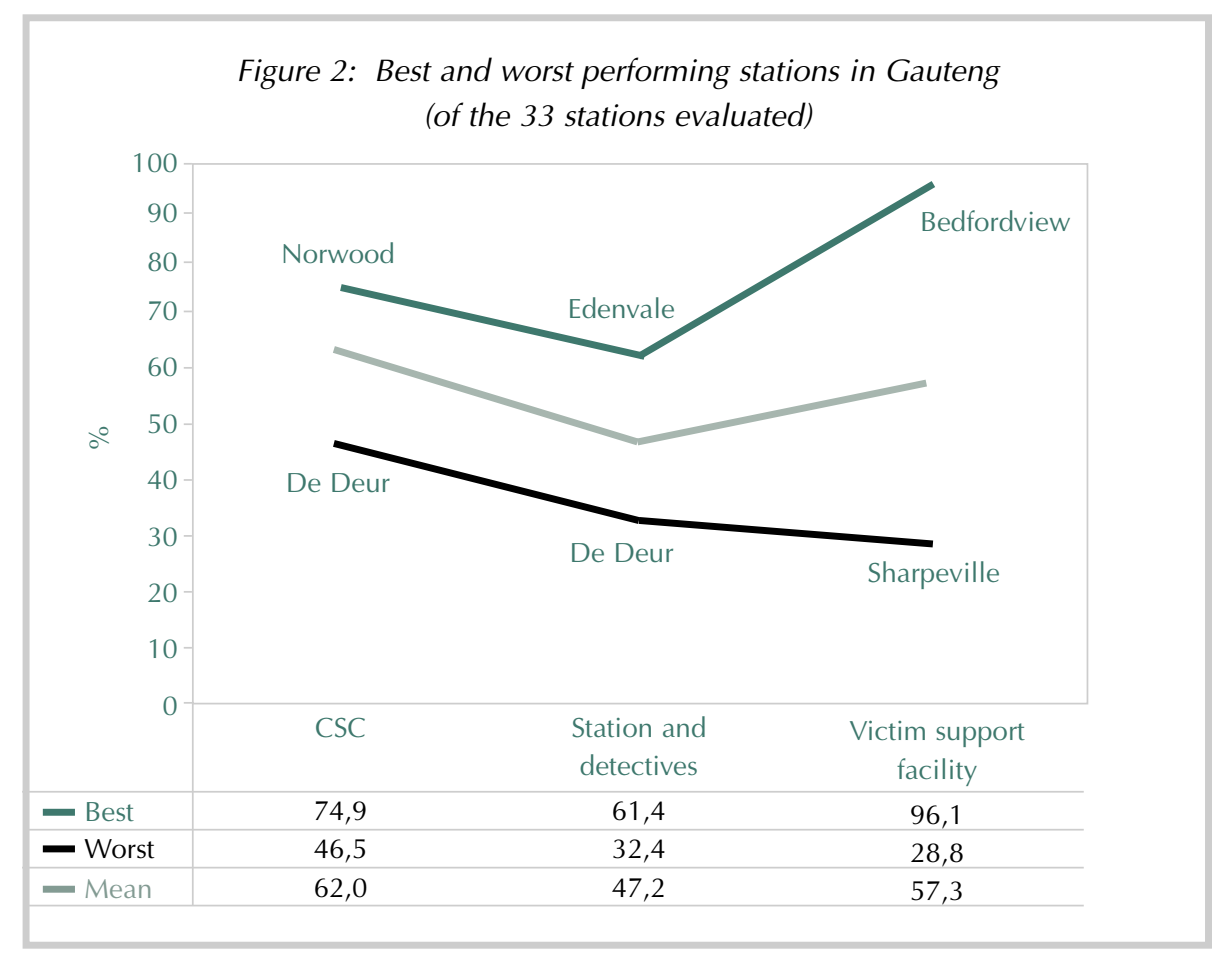

\section{Overall performance}

The results, although not surprising, highlight many often overlooked issues which can be simply rectified to present a neater, more user-friendly environment in which the police can offer a more sympathetic and professional service.

Bearing in mind that only 33 stations (out of 121 police stations in Gauteng) were evaluated, Norwood scored the highest in terms of its CSC service, Edenvale for its detective component, and Befordview for its victim support facility. De Deur and Sharpeville in the Vaal area scored the lowest (Figure 2).

Stations which could be regarded as consistent in their service delivery since they reflect average scores across the three focus areas are Johannesburg Central, Booysens, Kwa Thema, Diepkloof, Moroka and Vereeniging. Many of the stations scored above average for two of the focus areas but were considerably below in the third.

Some of the stations that scored the lowest in the Community Service Centre did so because of the inadequacy of the facility, for example Yeoville and Meyerton. It must also be noted that the indicators for professionalism and attitude tested in the survey are highly subjective, with expectations and points of reference differing widely for different individuals and communities. People in wealthier or more commercial areas tend to be more demanding of their police station whereas those in former township or principally residential areas, where there are higher levels of unemployment, are less demanding.

In general, most clients leaving the police station had positive views of the police. Figure 3 indicates that $61 \%$ of respondents (who had just had dealings with the CSC) said the police were either competent, friendly, effective or efficient. The objective of the SPPS programme is, through further improving service delivery, to convert the views of the remaining $39 \%$. While corruption is the main complaint about the police, this is based on general perceptions rather than actual experience: respondents have most often not had any personal experiences of corruption within the SAPS.

Respondents were also asked whether their impressions of the police had been affected by their visit to the station, and if yes, whether the visit improved or worsened their opinion. Just over half 
Figure 3: 'When you talk amongst your friends, what is your perception of the police?', all 33 Gauteng stations $(n=802)$

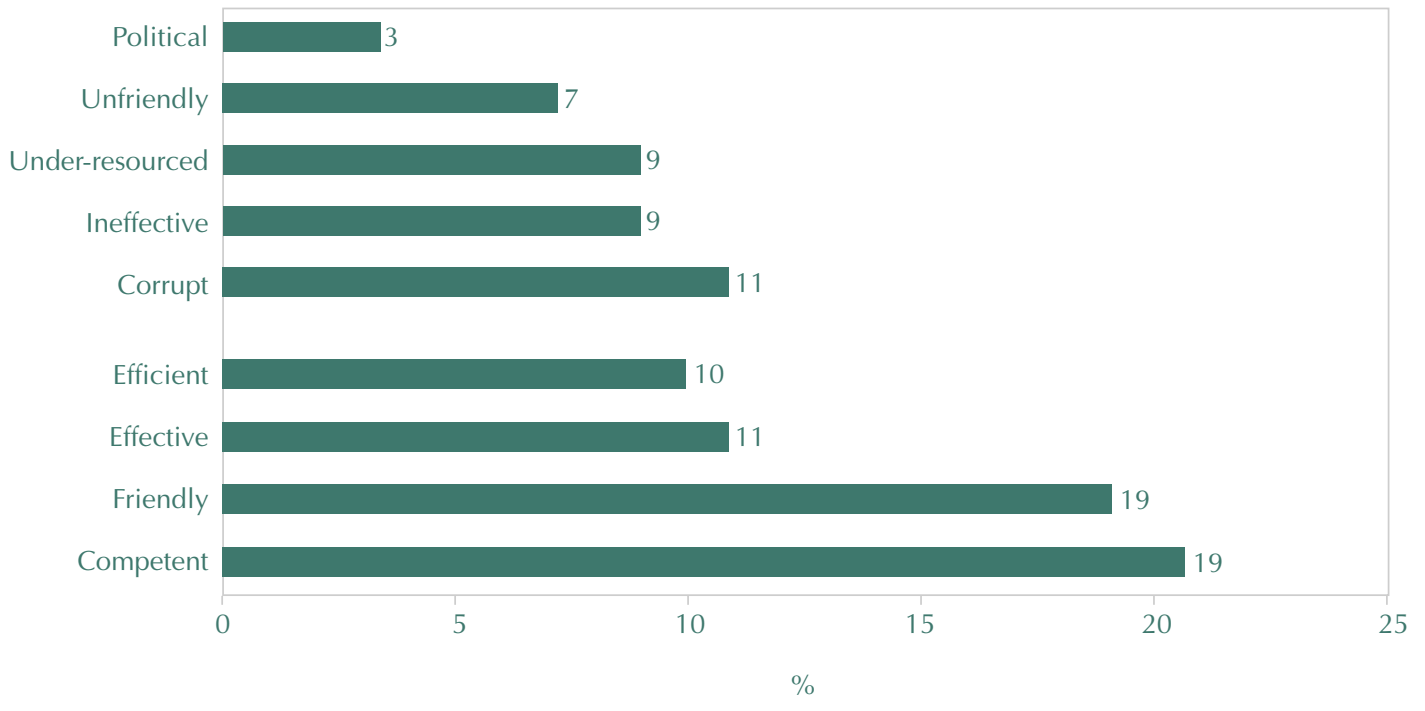

(53\%) said their opinion had changed as a result of their visit, and of these, a clear majority $(78 \%)$ reported an improvement. Just over one fifth $(22 \%)$ said their opinion had worsened.

\section{Views on the CSC}

Suggestions on how the Client Service Centre could be made more user-friendly revolved exclusively around the existing indicators about which clients were questioned. These include making available more seating and chairs (43\%), more plants $(41 \%)$ and pictures $(21 \%)$, and cleanliness and tidiness (39\%). Human resource issues were also raised as suggestions, such as training (12\%) and making staff available (8\%).

Generally the communication skills of members in the CSC were regarded as good to excellent. By comparison, the attitude of police officials, their application of knowledge to the job and telephone etiquette were rated 'average'. A particularly positive finding was that the length of time taken to deal with customers in the CSC was minimal in most stations.

\section{Views on detectives}

The follow-up interviews that canvassed opinion on the detectives indicated that generally the attitude of detectives was excellent but that their communication skills were lacking. Of concern is that respondents rated the detectives' referral to victim support as 'poor', and their feedback to victims on the progress with their cases as 'very poor'. This is very clearly reflected in Figure 4 which shows what victims expected of detectives at the time they were interviewed for this study (in other words, after their initial contact with detectives).

The results are encouraging in the sense that nearly two thirds of victims want information: either on the progress of their case $(60 \%)$ or on court proceedings $(4 \%)$. Providing information should be much less complicated than arresting suspects (only $13 \%$ expected this) or recovering goods (expected by only $9 \%$ of respondents). No doubt the high case loads facing most detectives hampers their ability to provide feedback to victims. Nevertheless, given the clear need expressed in the study, as well as the obvious implications of this aspect of police work for achieving convictions, solutions must be found.

\section{Improving police service delivery}

Many police officials probably don't realise that they have a considerable knowledge of criminal procedures with which they are able to, and 
Figure 4: Respondents' expectations of detectives at the time they were interviewed

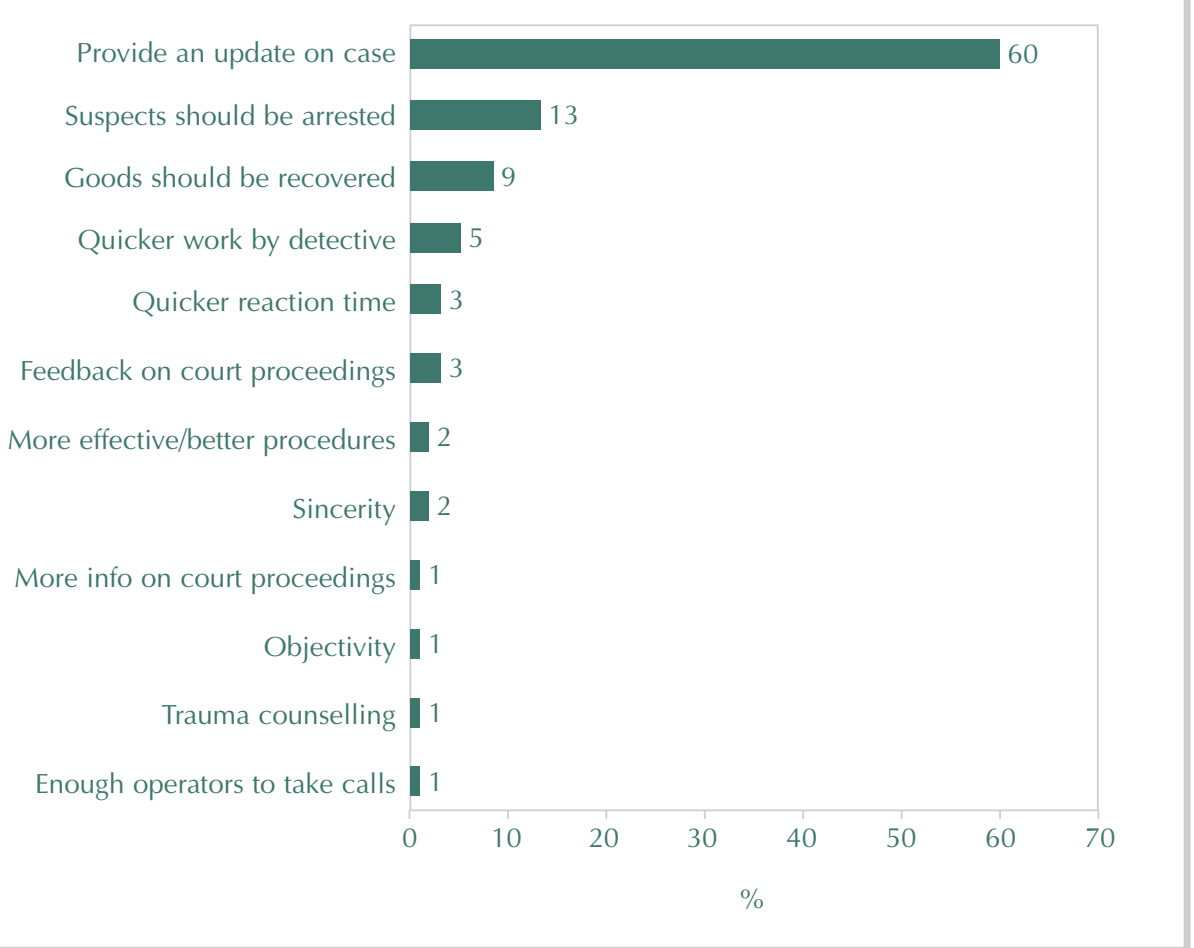

should, assist and inform victims. And while SAPS members have become accustomed to the horror of crime that they deal with every day of their lives, many of those who arrive at their Client Service Centres are first-time victims who are shocked and traumatised by their first exposure to crime.

There exists, therefore, great opportunity for police officials to understand the important and valuable roles that they can play in offering a sympathetic and professional first-line service to the public. This is the first step in eliciting a positive response from their clients, rather than the somewhat dissatisfied responses which one is used to hearing.

Many of the indicators for achieving the criteria are matters of police management and discipline which can be easily overlooked. The results of the baseline study have been presented to the SAPS Area Commissioners, station commissioners and partnership teams. It is hoped that by drawing attention to these issues, station managers will be encouraged to address them. The challenge is now out for all 33 stations covered in the study, with their partners' assistance, to achieve $90-100 \%$ in all ten criteria in all three focus areas.

BAC's role is to assist and advise the partnerships, to provide tools for the station to record their progress, to supply the stations with posters of participation and victim support awareness, and to conduct the re-evaluation.

While the issues of housekeeping, aesthetics and efficiency can be thus addressed, the deeper issues of professionalism, attitude and competence that underlie consistently excellent service provision require comprehensive customer care training for all members working in the CSC. To this end, BAC has entered into a joint proposal with Tshwane University of Technology in Pretoria to conduct a comprehensive customer care awareness programme for 1,155 members across the 33 SPPS police stations, starting this year. 